\title{
SCIDOC
}

\author{
International Journal of Dentistry and Oral Science (IJDOS) \\ ISSN: 2377-8075
}

\section{Assessment Of Knowledge, Attitude And Practice Survey On Endodontic Failure Among Endodontists, Post Graduates And General Practitioners In South Indian Population - A Survey}

Research Article

\author{
Kalyani Behera .A $A^{1}$ S.Delphine Priscilla Antony ${ }^{2 *}$, Haripriya .S ${ }^{2}$
}

${ }^{1}$ Department of Conservative Dentistry and Endodontics, Saveetha Dental College and Hospital, Saveetha Institute of Medical and Technical Science, Saveetha University, India.

${ }^{2}$ Senior Lecturer, Department of Conservative Dentistry and Endodontics, Saveetha Dental College and Hospital, Saveetha Institute Of Medical and Technical Science, Saveetha University, India.

\section{Abstract}

The causes of endodontic failures are due to the variations in the anatomy of the teeth, the presence of additional root canals, lateral canals, depend on technical, biological and iatrogenic factors so the correct diagnosis, optimal mechanical and chemical preparation with three- dimensional obturation of the root canal will be the main goal of endodontic treatment. Having knowledge about the relation between these factors may help in increasing the chances of preventing the possible endodontic treatment failures. The questionnaire was closed- ended type consisting 15 questions, of which 5 were knowledge- baked, 5 were attitude based, and 5 were practice -based questions. The questionnaire contained multiple responses. The answers to each question were numerically coded, and the data were entered in the SPSS software. The results were analyzed by descriptive statistics including frequencies and percentages.In the study, it was seen that the overall mean and standard deviation of knowledge score (53.4\%), attitude $(44 \%)$ and practice $(61 \%)$. Dentists, being members of the healthcare profession, should know about endodontic mishaps and its management which may occur during procedure. Only 56.4\% areaware of endodontic mishaps and its management according to the study.

Keywords: Root Canal Treatment; Endodontic Failures; Retreatment.

\section{Introduction}

Endodontic failure is a recurrence of a clinical symptom with well definedperiapical radiolucency, the success rate was upto $86-98 \%$. The factors which causes endodontic failure are the persistence of bacteria (Intra- canal and Extra- canal), Inadequate filling of the canal (canals that are poorly cleaned and obturated), overextension of Root filling materials, Improper coronal seal (Leakage), Untreated canals (both Major and accessory), Iatrogenic procedural errors such as poor access cavity design, complications of instrumentation (ledges, perforations (or) separated instruments. All endodonticallytreated should be evaluated clinically as well as radiographically [7]. To ensure the success of the treatment patients should be given appointments for follow up.

The important role of an endodontic treatment is to retain the tooth in the oral cavity. The purpose of root canal treatment is to block all the passages for causing infections in the root canal lumen and to form a fluid tight seal on apical foramen of tooth, thereby leakage in the root canal system can be avoided and occurrence of secondary infection is prevented [5]. Endodontic failures can also be related for treating wrong tooth, missed canals, damage to existing restorations, access cavity perforations, crown fractures, instrumentation with ledge formation, cervical canal perforations, mid root perforations, apical perforations, separated instruments, foreign objects, canal blockage and obturation related due to over extended, under- extended root canal fillings and vertical root fractures $[19,3,10]$. Endodontic treatment is fairly predictable in nature with reported success rate up to $86-98 \%$ $[18,4,6]$ ("Impact of case difficulty on endodontic mishaps in an undergraduate student clinic", 2019).

The aim of Endodontic treatment should be thorough cleaning and debridement of the root canal of an infected pulp, and filled with an inert material, thus preventing (or) minimizing any chanc-

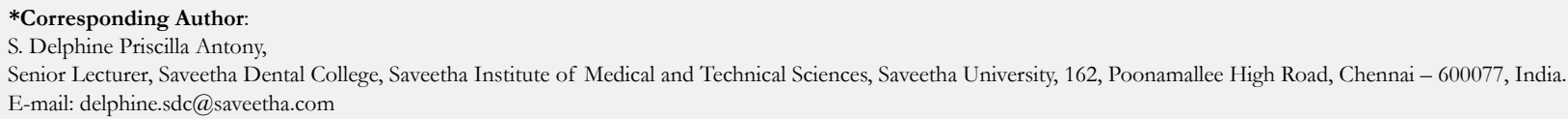

Citation: Kalyani Behera .A, S.Delphine Priscilla Antony, Haripriya .S. Assessment Of Knowledge, Attitude And Practice Survey On Endodontic Failure Among Endodontists, Post Graduates And General Practitioners In South Indian Population - A Survey. Int J Dentistry Oral Sci. 2020;S10:02:0020:106-112. doi: http://dx.doi.org/10.19070/2377-8075-SI02-0100020

Copyright: S. Delphine Priscilla Antony ${ }^{\circ} 2020$. This is an open-access article distributed under the terms of the Creative Commons Attribution License, which permits unrestricted use, distribution and reproduction in any medium, provided the original author and source are credited. 
es of reinfection.

\section{Materials And Methods}

A total of 220 questionnaires were distributed with the guidance of previous studies, the questionnaires were developed. A web based survey tool was used to create the survey. The survey was sent by email to Endodontists, post - graduates, General dental practitioners in the South Indian population. The participants were asked to answer 15 Multiple choice questions. The questions were based on general approach towards Knowledge, attitude and practice towards Endodontic failures.

\section{Results And Discussion}

200 respondents were received from the respondents. Among 200 responses received from the participants, $58.9 \%$ consisted of males and $41 \%$ females of the participants [Figure 1] were of mean group age (43\%) age- (25- $30 \mathrm{yrs})$ followed by mean age group (52\%) age- (31- 40 yrs) of the 200 respondents [Figure 2 ] and it was seen that the overall mean and standard deviation of knowledge score $(53.4 \%)$, attitude (44\%) and practice (61\%). Survey results are explained in the figures given below (Figures 2-16).

In the present study of era, emerging new advent methods and tools, therapeutic and controlling measures applicable to the pulp and periradicular diseases have been developed significantly to an

Figure 1. Bar chart showing comparison of responses based on gender to the field of practice in the survey, where $\mathrm{X}$ axis represents the field of practice and $\mathrm{Y}$ axis represents the number of respondents. Higher number of males reported (119) when compared to females ( 81) and there is no significant difference in responses between males and females

( Chi square test;(p value $>0.05$ )- Not Significant [ Blue- Female; Green- Male]

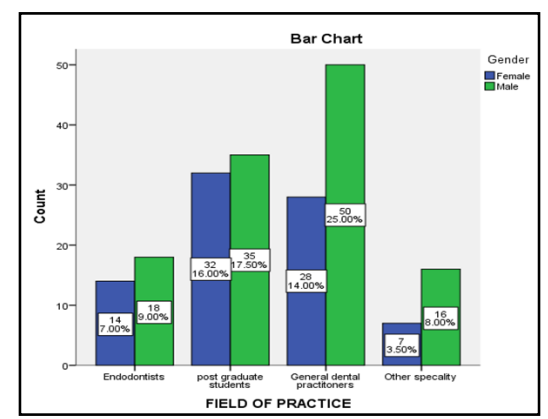

Figure 2. Bar chart showing the age distribution of the respondents to the field of practice involved in the survey, where $X$ axis represents the field of practice and $\mathrm{Y}$ axis represents the number of respondents. Higher number among (19-25 years) of age groups was 2.5 times higher when compared to other age groups and this was found to be statistically significant.

( Chi square test;(p value < 0.05)- Significant [ Blue- 19-25yrs, Green-25-30 yrs, Grey- 31-40 yrs and Violet- 41-50 yrs]

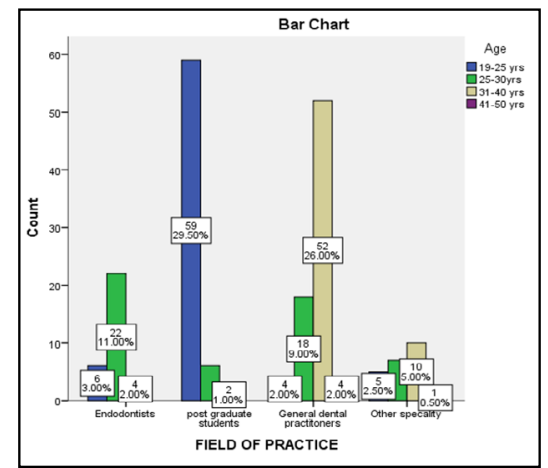

Figure 3. Bar chart showing the correlation between the field of practice and their response regarding common missed canals, where $\mathrm{X}$ axis represents the field of practice and $\mathrm{Y}$ axis represents the number of respondents and there was significant difference in the responses obtained from Endodontists,generalpractitioners,postgraduates and other speciality.( Chi square test; ( $p$ value < 0.05)- Significant [Blue- Mesiobuccal canal of maxillary first molars, Green- Mesiobuccal canal of maxillary second molars, Grey- Mesiolingual canal of mandibular second molars, Violet- Medial mesial canal of mandibular second molars].

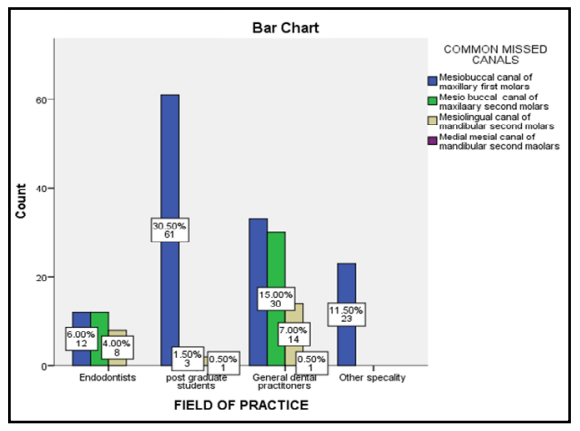


Figure 4. Bar chart showing the correlation between the field of practice and their response regarding common cause of endodontic failure, where $\mathrm{X}$ axis represents the field of practice and $\mathrm{Y}$ axis represents the number of respondents and there is no significant difference in the responses obtained from Endodontists,generalpractitioners,postgraduates and other speciality ( Chi square test;(p value $>0.05$ )- Not Significant [ Blue- Instrument separation, Green- Canal blockage, Grey- Ledge formation and Violet- Perforations]

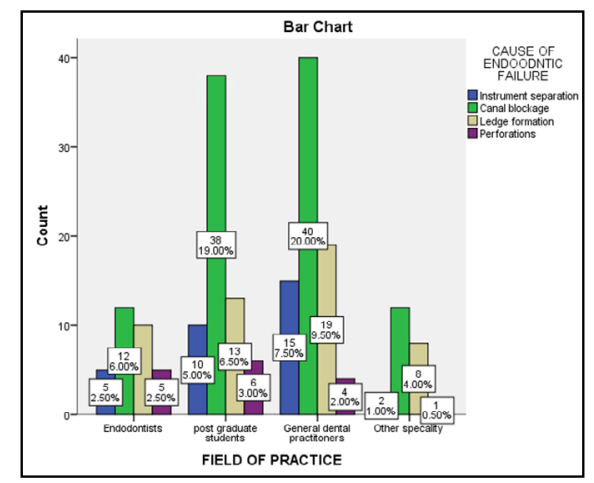

Figure 5. Bar chart showing the correlation between the field of practice and their response regarding Factors affecting failure of endodontic therapy, where $\mathrm{X}$ axis represents the field of practice and $\mathrm{Y}$ axis represents the number of respondents and there was significant difference in the responses obtained from Endodontists,generalpractitioners,postgraduates and other speciality.( Chi square test;(p value $<0.05$ )- Significant [Blue- Diagnosis and a treatment planning, Green- Radiographic interpretation, Grey- Anatomy of the tooth and root canal system, Violet- Debridement of root canal system and Yellow- All of the above].

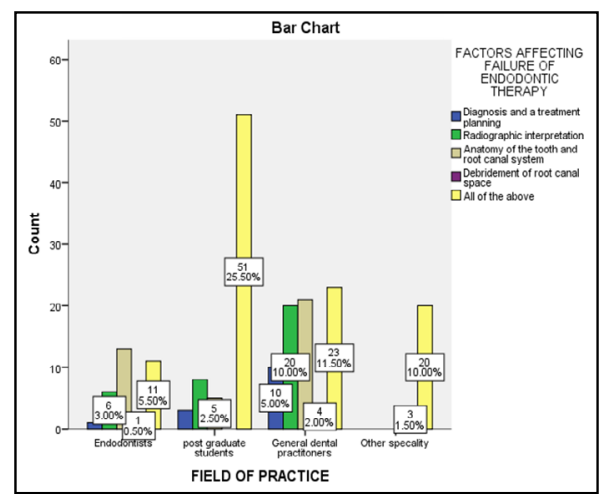

Figure 6. Bar chart showing the correlation between the field of practice and their response regarding ledge formation, where $\mathrm{X}$ axis represents the field of practice and $\mathrm{Y}$ axis represents the number of respondents and there was significant difference in the responses obtained from Endodontists,generalpractitioners,postgraduates and other speciality.( Chi square test; (p value < 0.05)- Significant [Blue- Over enlargement of small curved canals, Green- Calcification, Grey- Multiple canals and Violet- straight - Straight canals].

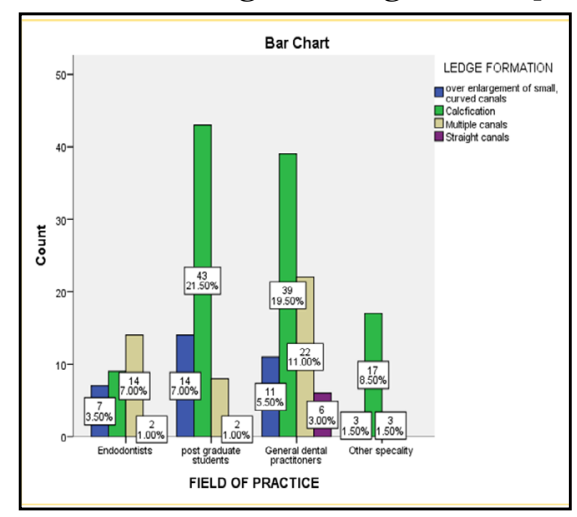

extent that most of the teeth pulled out because of root damages and dental caries in the past, which are now maintained by undergoing Endodontic treatment with a relatively good prognosis [13]. Many teeth require RCT due to caries, trauma, (or) other reasons. Considering millions of people needing RCT, patients should be aware of the success rate and soundness of this method. Investigations have revealed that the majority of root canal failures are due to procedural accidents [14]. Moreover, based on these findings, the level of students' knowledge about treatment and prognosis is higher than their knowledge about the causes and prevention Methods.

Some of the most common procedural accidents include perforation of the pulp chambers during preparation of access cavity, creating ledges, broken instruments, root perforation, and a vertical root breakage [2]; such accidents can happen in various stages of Endodontic treatment such as developing access chamber, canal formation and cleaning, canal filling or preparation of 
Figure 7. Bar chart showing the correlation between the field of practice and their response regarding cause of perforation during access cavity, where $\mathrm{X}$ axis represents the field of practice and $\mathrm{Y}$ axis represents the number of respondents and there was significant difference in the responses obtained from Endodontists,generalpractitioners,postgraduates and other speciality. ( Chi square test;(p value < 0.05)- Significant [Blue-Improper size of the bur, Green- Lack of proper degree of axial inclination, Grey- Additional canals and Violet- Debris accumulation].

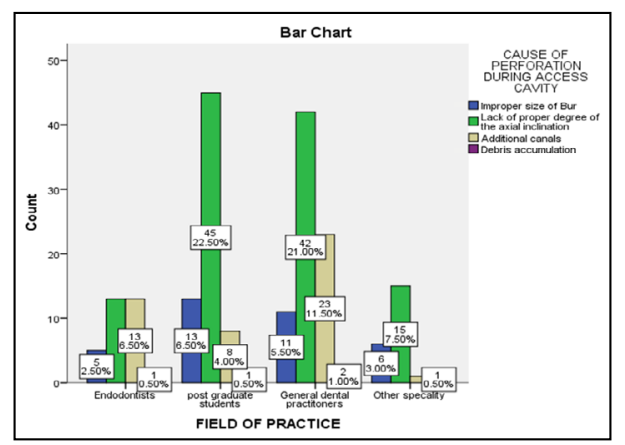

Figure 8. Bar chart showing the correlation between the field of practice and their response regarding, errors that happen during instrument separation, where $\mathrm{X}$ axis represents the field of practice and $\mathrm{Y}$ axis represents the number of respondents and there is no significant difference in the responses obtained from Endodontists,generalpractitioners,postgraduates and other speciality ( Chi square test;(p value $>0.05$ )- Not Significant Green-Inadequate lubrication, Grey- increased speed of instrumentation and violet- improper radiographic examination]

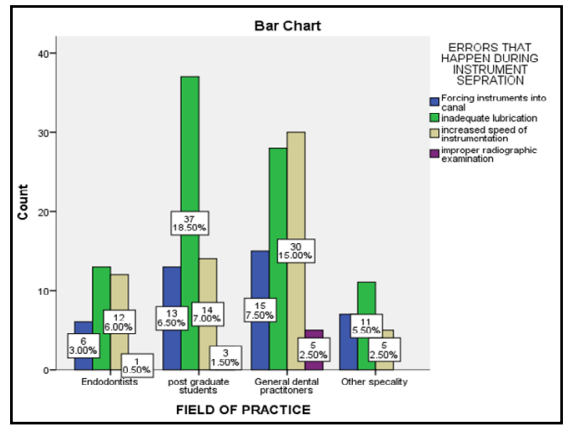

Figure 9. Bar chart showing the correlation between the field of practice and their response regarding,errors that happen during instrument separation, where $\mathrm{X}$ axis represents the field of practice and $\mathrm{Y}$ axis represents the number of respondents and there was significant difference in the responses obtained from Endodontists,generalpractitioners, postgraduat es and other speciality.( Chi square test;(p value < 0.05)- Significant [Blue- Accurate working length measurement, Greenproper cleaning and shaping, Grey- proper radiographic examination, Violet- All of the above]

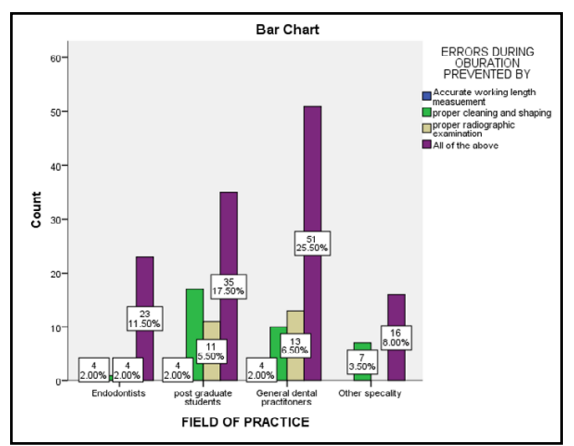

Figure 10. Bar chart showing the correlation between the field of practice and their response regarding Is age is successful for endodontic treatment, where $\mathrm{X}$ axis represents the field of practice and $\mathrm{Y}$ axis represents the number of respondents and there is no significant difference in the responses obtained from Endodontists,generalpractitioners,postgraduates and other speciality ( Chi square test;(p value $>0.05$ )- Not Significant [ Blue- yes, Green- no and Grey- may be]

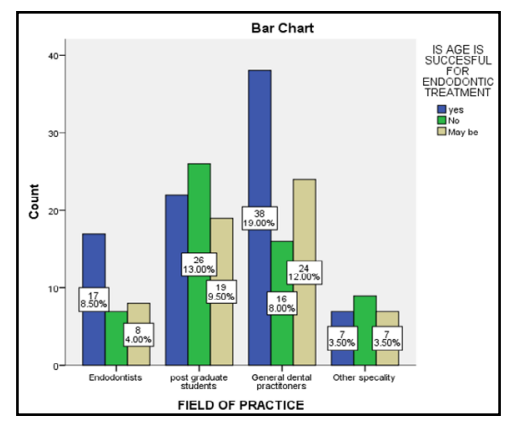


Figure 11. Bar chart showing the correlation between the field of practice and their response regardingIsendodontically treated tooth is always successful, where $X$ axis represents the field of practice and $Y$ axis represents the number of respondents and there is no significant difference in the responses obtained from Endodontists,generalpractitioners,postgr aduates and other speciality (Chi square test;(p value $>0.05)$ - Not Significant[ Blue- yes, Green- no, Grey- sometimes and Violet- not always]

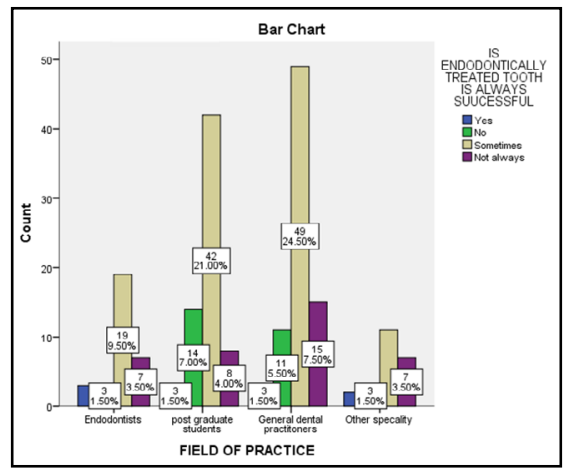

Figure 12. Bar chart showing the correlation between the field of practice and their response regarding In which file is not retrievable easily, where $X$ axis represents the field of practice and $Y$ axis represents the number of respondents and there is no significant difference in the responses obtained from Endodontists,generalpractitioners,postgraduates and other speciality. (Chi square test;(p value $>0.05)$ - Not Significant [ Blue- apical third, Green- middle third and grey- coronal third].

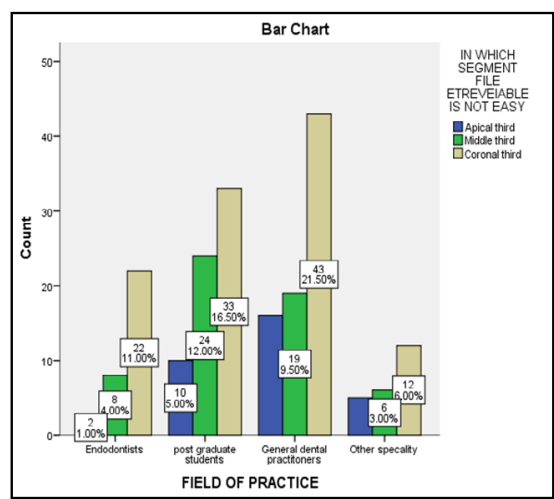

Figure 13. Bar chart showing the correlation between the field of practice and their response regarding Ledging bypassed by, where $\mathrm{X}$ axis represents the field of practice and $\mathrm{Y}$ axis represents the number of respondents and there is no significant difference in the responses obtained from Endodontists,generalpractitioners,postgraduates and other speciality (Chi square test;(p value $>0.05$ )- Not Significant [Blue- using teardrop shaped file, Green- using air rotor with long bur, Grey- using EDTA and violet- Extraction of tooth].

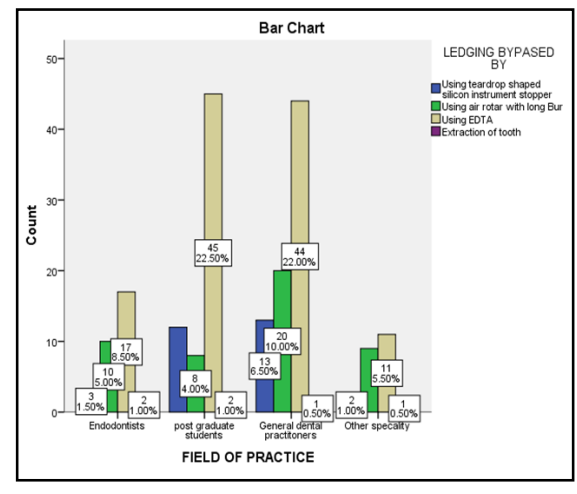

post chambers. Being unaware of the causes (Teja KV 2018) [15], prevention and method of treating procedural accidents cause different complications such as canal blockage, Incomplete canal cleaning (or) various physical, chemical and thermal stresses. Furthermore, being aware of the procedural accidents can be useful to prevent them. The therapists should also know how to diagnose and treat such procedural accidents, reviewed the outcome of Endodontic procedural errors $[8,9]$. They indicated that Endodontic procedural errors are not the direct cause of treatment failure [16]. Many authors reported that one of the stresses of reasons for furcation perforations, Missed canals, over perfora- tions ,strip perforations, kedge , zipping, broken Files, and apical perforation ( $\mathrm{R}$ et al., 2019). There has not been any research to compare the level of knowledge of Male and female respondents about Endodontic procedural accidents, However, increasing hours of practical teaching and workshops can be helpful in increasing students' awareness in this area. Furthermore, it is essential to have knowledge about the procedural accidents [12]. Moreover, therapeutic and diagnostic methods and the impacts of such accidents on prognosis should be learned [8]. Most of the pertinent problems can be prevented by observing the fundamental principles of diagnosis, tooth selection, treatment plan, 
Figure 14. Bar chart showing the correlation between the field of practice and their response regarding materials used in management of perforations, where $\mathrm{X}$ axis represents the field of practice and $\mathrm{Y}$ axis represents the number of respondents and there was significant difference in the responses obtained from Endodontists,generalpractitioners,postgraduates and other speciality.( Chi square test; (p value < 0.05)- Significant [ Blue- Zinc oxide eugenol, Green- MTA, Grey- Dycal and Violet- composites]

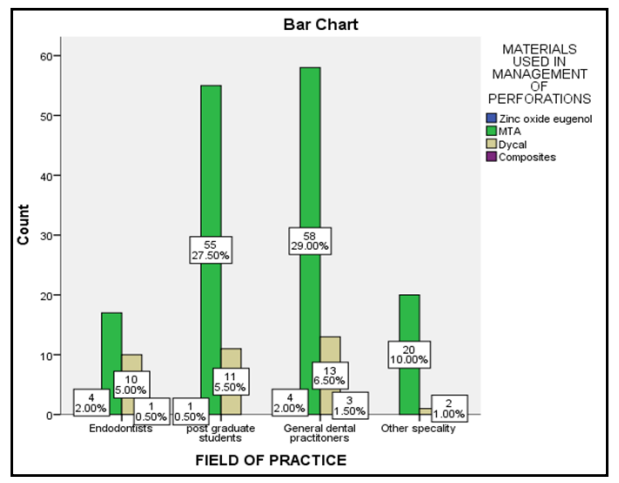

Figure 15. Bar chart showing the correlation between the field of practice and their response regarding best method to treat endodontic failure, where $\mathrm{X}$ axis represents the field of practice and $\mathrm{Y}$ axis represents the number of respondents and there is no significant difference in the responses obtained from Endodontists,generalpractitioners,postgraduates and other speciality ( Chi square test; $(p$ value $>\mathbf{0 . 0 5}$ )- Not Significant [Blue- non surgical root canal treatment, Green- surgical method, Grey- leave as it is and Violet- Extraction]

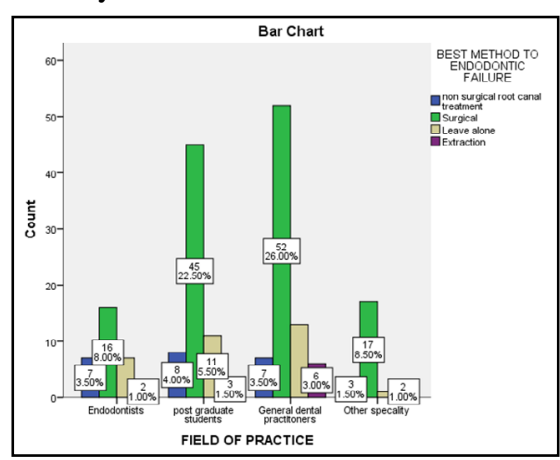

Figure 16. Bar chart showing the correlation between the field of practice and their response regarding missed canal during access cavity preparation, where $X$ axis represents the field of practice and $Y$ axis represents the number of respondents and there is no significant difference in the responses obtained from Endodontists,generalpractitioners,postgraduates and other speciality ( Chi square test;(p value $>0.05$ )- Not Significant [ Blue-ultrasonics, Green- methylene blue, Grey- champagne bubble test and violet- magnification loupes]

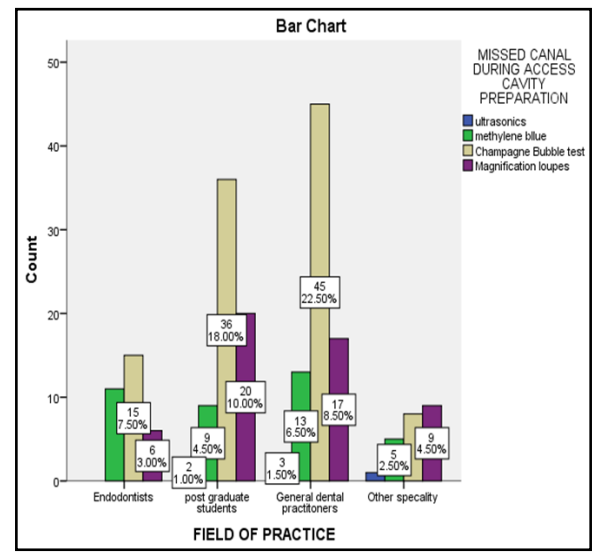

preparation by observing the fundamentals. Principles of diagnosis, tooth selection, treatment plan, preparation of access cavity, canal formation and cleaning, canal filling and preparation of post chamber [20].

\section{Conclusion}

The clinician must practice careful treatment strategies for working length, precautions against over instrumentation. The direct cause of treatment failures are the endodontic procedural errors, with high enhanced magnification by operating microscope, almost all procedural errors during endodontic therapy can be minimised.

\section{References}

[1]. Haug SR, Solfjeld AF, Ranheim LE, Bårdsen A. Impact of Case Difficulty on Endodontic Mishaps in an Undergraduate Student Clinic. J Endod. 2018 Jul;44(7):1088-1095. PubmedPMID: 29803337. 
[2]. Janani K, Palanivelu A, Sandhya R. Diagnostic accuracy of dental pulse oximeter with customized sensor holder, thermal test and electric pulp test for the evaluation of pulp vitality: an in vivo study. Brazilian Dental Science. 2020 Jan 31;23(1):8-p.

[3]. JOHNSON W. Obturation of the cleaned and shaped root canal. Pathways of the Pulp. 2011:358-62.

[4]. Jose J, Subbaiyan H. Different treatment modalities followed by dental practitioners for ellis class 2 fracture-A questionnaire-based survey. The Open Dentistry Journal. 2020 Feb 18;14(1).

[5]. Kumar D, Antony SD. Calcified canal and negotiation-A review. Research Journal of Pharmacy and Technology. 2018 Aug 1;11(8):3727-30.

[6]. Manohar MP, Sharma S. A survey of the knowledge, attitude, and awareness about the principal choice of intracanal medicaments among the general dental practitioners and nonendodontic specialists. Indian J Dent Res. 2018 Nov-Dec;29(6):716-720. doi: 10.4103/ijdr.IJDR_716_16. PubmedPMID: 30588997.

[7]. Mirikar P, Shenoy A, Mallikarjun GK. Nonsurgical management of endodontic mishaps in a case of radix entomolaris. J Conserv Dent. 2009 Oct;12(4):169-74. PubmedPMID: 20543928.

[8]. Hussainy SN, Nasim I, Thomas T, Ranjan M. Clinical performance of resinmodified glass ionomer cement, flowable composite, and polyacid-modified resin composite in noncarious cervical lesions: One-year follow-up. J Conserv Dent. 2018 Sep-Oct;21(5):510-515. PubmedPMID: 30294112.

[9]. Nandakumar M, Nasim I. Comparative evaluation of grape seed and cranberry extracts in preventing enamel erosion: An optical emission spectrometric analysis. J Conserv Dent. 2018 Sep-Oct;21(5):516-520. Pubmed PMID: 30294113.

[10]. Noor SS. Chlorhexidine: Its properties and effects. Research Journal of Pharmacy and Technology. 2016 Oct 1;9(10):1755.

[11]. Colombo M, Bassi C, Beltrami R, Vigorelli P, Spinelli A, Cavada A et al. Radiographic technical quality of root canal treatment performed by a new rotary single-file system. Ann Stomatol (Roma). 2017 Jul 3;8(1):18-22.pubmed PMID: 28736602.
[12]. Rajendran R, Kunjusankaran RN, Sandhya R, Anilkumar A, Santhosh $\mathrm{R}$, Patil SR. Comparative evaluation of remineralizing potential of a paste containing bioactive glass and a topical cream containing casein phosphopeptide-amorphous calcium phosphate: An in vitro study. Pesquisabrasileiraemodontopediatria e clinicaintegrada. 2019;19.

[13]. Ramamoorthi S, Nivedhitha MS, Divyanand MJ. Comparative evaluation of postoperative pain after using endodontic needle and EndoActivator during root canal irrigation: A randomised controlled trial. AustEndod J. 2015 Aug;41(2):78-87. PubmedPMID: 25195661.

[14]. Ramanathan S, Solete P. Cone-beam Computed Tomography Evaluation of Root Canal Preparation using Various Rotary Instruments: An in vitro Study. J Contemp Dent Pract. 2015 Nov 1;16(11):869-72. PubmedPMID: 26718293.

[15]. Teja KV, Ramesh S, Priya V. Regulation of matrix metalloproteinase-3 gene expression in inflammation: A molecular study. J Conserv Dent. 2018 NovDec;21(6):592-596. PubmedPMID: 30546201.

[16]. Ravinthar K. Recent advancements in laminates and veneers in dentistry. Research Journal of Pharmacy and Technology. 2018 Feb 1;11(2):785-7.

[17]. Rajakeerthi R, Nivedhitha MS. Natural Product as the Storage medium for an avulsed tooth-A Systematic Review. Cumhuriyet Dental Journal. 2019;22(2):249-56

[18]. Siddique R, Sureshbabu NM, Somasundaram J, Jacob B, Selvam D. Qualitative and quantitative analysis of precipitate formation following interaction of chlorhexidine with sodium hypochlorite, neem, and tulsi. J Conserv Dent. 2019 Jan-Feb;22(1):40-47. PubmedPMID: 30820081.

[19]. Teja KV, Ramesh S. Is a filled lateral canal - A sign of superiority? J Dent Sci. 2020 Dec;15(4):562-563. PubmedPMID: 33505634.

[20]. Tzanetakis GN, Kontakiotis EG, Maurikou DV, Marzelou MP. Prevalence and management of instrument fracture in the postgraduate endodontic program at the Dental School of Athens: a five-year retrospective clinical study. J Endod. 2008 Jun;34(6):675-8. PubmedPMID: 18498887. 